\title{
LA-UR-15-28061
}

Approved for public release; distribution is unlimited.

Title: $\quad$ Taking Steps to Protect Against the Insider Threat

Author(s): $\quad$ Pope, Noah Gale

Williams, Martha

Lewis, Joel

Pham, Thomas

Intended for: $\quad$ Paper for IAEA.

Issued: 2015-10-16 
Disclaimer:

Los Alamos National Laboratory, an affirmative action/equal opportunity employer,is operated by the Los Alamos National Security, LLC for the National NuclearSecurity Administration of the U.S. Department of Energy under contract DE-AC52-06NA25396. By approving this article, the publisher recognizes that the U.S. Government retains nonexclusive, royalty-free license to publish or reproduce the published form of this contribution, or to allow others to do so, for U.S. Government purposes. Los Alamos National Laboratory requests that the publisher identify this article as work performed under the auspices of the U.S. Departmentof Energy. Los Alamos National Laboratory strongly supports academic freedom and a researcher's right to publish; as an institution, however, the Laboratory does not endorse the viewpoint of a publication or guarantee its technical correctness. 
$\underline{\text { Title }}$

Taking Steps to Protect Against the Insider Threat

Authors

Martha Williams, Tetra Tech HEI; Joel Lewis, Gregg Protection Services; Thomas Pham, United States

Nuclear Regulatory Commission; Noah Pope, Los Alamos National Laboratory

Synopsis

Research reactors are required (in accordance with the Safeguards Agreement between the State and the IAEA) to maintain a system of nuclear material accounting and control for reporting quantities of nuclear material received, shipped, and held on inventory. Enhancements to the existing accounting and control system can be made at little additional cost to the facility, and these enhancements can make nuclear material accounting and control useful for nuclear security. In particular, nuclear material accounting and control measures can be useful in protecting against an insider who is intent on unauthorized removal or misuse of nuclear material or misuse of equipment. An enhanced nuclear material accounting and control system that responds to nuclear security is described in NSS-25G, Use of Nuclear Material Accounting and Control for Nuclear Security Purposes at Facilities, which is scheduled for distribution by the IAEA Department of Nuclear Security later this year. Accounting and control measures that respond to the insider threat are also described in NSS-33, Establishing a System for Control of Nuclear Material for Nuclear Security Purposes at a Facility During Storage, Use and Movement, and in NSS-41, Preventive and Protective Measures against Insider Threats (originally issued as NSS-08), which are available in draft form. This paper describes enhancements to existing material control and accounting systems that are specific to research reactors, and shows how they are important to nuclear security and protecting against an insider.

\section{Taking Steps to Protect Against the Insider Threat}

The threat associated with misuse of nuclear material has changed over recent years, and the approach to combating that threat needs to change in response to the changing threat. One of the more serious concerns is the possibility that a facility insider (i.e. someone with authorized access to the facility and its nuclear material) might steal nuclear material for nefarious purposes. One of the strongest measures that a research reactor can take to combat the insider threat is to improve its nuclear material accounting and control (NMAC) system.

States are required by existing Safeguards Agreements to establish a State System of Accounting and Control. In concert with this requirement, the State requires its nuclear facilities to establish facility systems to account for and control nuclear material. The facility systems also prepare Safeguards reports. States and facilities may voluntarily enhance existing programs to make them more effective in responding to the insider threat. Enhancements to an existing NMAC system cost the nuclear facility very little in comparison with the cost of establishing new measures, yet they make the existing system 
more useful for nuclear security. Because NMAC systems vary from State to State and from facility to facility, because system effectiveness in responding to nuclear security issues also varies, and because the threat differs from State to State, some existing NMAC systems may require more enhancements for nuclear security than others.

(A facility insider might also misuse radioactive material produced or used in a research reactor. The same NMAC system used for nuclear material can also be used against the threat of misuse of radioactive material.)

\section{NMAC AND THE INSIDER}

NMAC systems can be effective in detecting and deterring insider activities at the facility level. Three of the most important components of an effective NMAC system are complete records, periodic physical inventory taking and nuclear material control.

Records should be prepared that document every activity that occurs at the facility involving nuclear material the facility. The records should tell the current location of every item of nuclear material. They should include information concerning who did what with the nuclear material, when it was done, where the nuclear material was located before the activity, and where it was located when the activity was complete. Without records of nuclear material and where it is, questions of theft or misuse cannot be answered. Nuclear security relies on records to resolve such questions.

A physical inventory should be taken at least once a year, and the results of the physical inventory taking should be compared with the records that list what the facility should have (i.e. the perpetual or book inventory). Any discrepancies should be investigated and resolved. The results of physical inventory taking tell if nuclear material is missing. The results also tell whether the NMAC system is effective for assuring the security of nuclear material. If the results of the physical inventory taking indicate that nuclear material is missing, there is a problem with the system used to keep it secure. If the results of the physical inventory taking indicate that nuclear material is merely in the wrong location, there is a problem with the systems for controlling it and maintaining records of its location.

Nuclear material should always be under control. Nuclear material that is left out on a table in an unlocked room when it is not being used is more vulnerable to theft or misuse. (This also applies to radioactive material.) Nuclear material that is not being used (and that is not under control while it is being used) is more vulnerable than material stored in a vault. Nuclear security cannot effectively protect against an insider without appropriate controls (whether they are administered through the NMAC system or by physical protection personnel).

These and other components of an NMAC system are described in detail in NSS-25G, Establishing a System for Control of Nuclear Material for Nuclear Security Purposes at a Facility during Storage, Use and Movement. The specific tools of an NMAC system applicable to research reactors are described in more detail in the following paragraphs. The section of NSS-25G where each element is described is also included. 


\section{NMAC SYSTEM ELEMENTS}

\section{Management}

(NSS-25G 4.4-4.32) The research reactor should have a written plan that will enable it to account for and control all items containing nuclear material. The plan should include forms for preparing records of all activities that involve nuclear material items; e.g. a form for documenting relocation of items from storage to the reactor, a form for documenting relocation of items from the reactor to the spent fuel pond, etc. The plan should designate responsibilities and authorities for the people responsible for receiving nuclear material items and all other activities related to it. The plan should describe training in accounting and control for all individuals with possible access to storage areas, the reactor, the spent fuel pond, or any other areas where nuclear material items might be located.

\section{Records}

(NSS-25G 4.33-4.59) Nuclear material at a research reactor generally consists of elements to be used in the reactor and instruments. It may also include targets. Complete records should be maintained of all activities involving nuclear material. These records include accounting records and operating records. The records maintained by the reactor engineer responsible for accounting reports are commonly referred to as the perpetual inventory records or the book records.

A complete historical record should be prepared for each item containing nuclear material when it is received. The record should be updated when the item is placed in storage (e.g. fresh fuel storage); any time it is relocated, if that occurs; when it is moved to the reactor; when it is moved from the reactor to the spent fuel pond; any time it is relocated within the spent fuel pond, if that occurs; when it is shipped offsite (e.g. to long-term storage); and when any other activities involving the nuclear material item occur. The record should always include the unique identification number of the item and the unique identification number of its location, including the original location (the "from" location) and the new location (the "to" location).

The records should show the identity and location of all items containing nuclear material, including storage and location in the reactor. If the records do not also include quantitative nuclear material data, supporting records should be available making it possible to assign or to calculate nuclear material quantities, including production, nuclear material loss, and decay. For fresh fuel, nuclear material quantities should include uranium and U-235; and for irradiated and spent fuel, nuclear material quantities should include uranium, U-235 and plutonium.

The history of every nuclear material item received by the research reactor should be readily available. As long as an item is on the research reactor site, its location should be up-to-date and accurate. If a problem occurs involving an item of nuclear material (e.g. an allegation of theft), records should make it possible to resolve the problem immediately.

\section{Physical Inventory Taking}


(NSS-25G 4.60-4.81) A physical inventory taking of all nuclear material items in the facility should be conducted at least once a year. Time between physical inventory takings should not exceed twelve months. Activities should be conducted by teams of at least two people. For fresh fuel items, identification numbers and location should be physically observed. Observing the identification numbers of items in the reactor and spent fuel pond may be difficult; however, identification numbers should be observed if possible (e.g. using binoculars). Records that document the results of the physical inventory taking should be maintained. If there are differences between the results of physical inventory taking and the book records, the differences should be investigated and resolved.

\section{Measurements and Measurement Quality Control}

(NSS-25G 4.82-4.107) Most nuclear material at a research reactor is contained in fuel elements, which are generally assigned measured values by the fuel manufacturer. The vendor values are updated using calculations to account for nuclear loss and gain during irradiation in the reactor. However, a research reactor may also possess sources containing nuclear material that are use for experiments or as targets. If nuclear material exists in forms other than fuel elements, provisions should be made for measuring it, and all measurements should be subject to a quality control program

Nuclear Material Control (NSS-25G 4.108-4.145)

Authorization of personnel and operations related to Nuclear Material

(NSS-25G 4.115) Use of the reactor should be controlled. Only authorized individuals should be allowed access to the reactor and storage areas. It should not be possible for a single individual acting alone to operate or use the reactor.

Two Person Rule

(NSS-25G 4.123) All activities involving nuclear material items should be conducted by at least two people. Receipt activities, physical inventory taking, relocations and all other activities involving nuclear material items should never be conducted by one individual working alone. Records of activities involving nuclear material items should be signed by at least two people, one of whom is involved in conducting the activity and another person who can attest to witnessing the activity. Records with date, time and signatures, should be prepared as the activity is conducted.

Item Monitoring

(NSS-25G 4.138) Between physical inventory takings, observation of a random sample of nuclear material item identities and locations can provide a degree of assurance that the records are accurate and complete.

Access Control

(NSS-25G 4.122-4.123) Access to nuclear material items should be controlled. Fresh fuel should be stored in a vault-like room with hardened walls, ceilings, and floors. If holes (e.g. ventilation holes) are 
necessary, the openings should be covered and alarmed. Doors to fresh fuel storage should be locked and alarmed. Access to the fresh fuel storage room should require two people. It should not be possible for a single individual to enter the fresh fuel storage area alone.

Access to the reactor and spent fuel areas should be controlled. Again, gaining access should require two people and it should not be possible for a single individual to enter these areas alone.

Access to equipment needed to move nuclear material items should be controlled. If the equipment requires keys for operation, the keys should be kept in a locked box and access to the box should require two people.

\section{Nuclear Material Movements}

(NSS-25G 4.146-4.160) When nuclear material items are received, the actual items should be checked to ensure that the items received are the items described in the shipping documents. Any differences should be investigated and resolved.

If nuclear material items are shipped off-site (e.g. for dry storage or return to the manufacturer), measures should be in place to ensure that the actual items shipped are those described in the shipping documents. Transfers off-site should be restricted to authorized recipients. If non-nuclear items are removed from the reactor or spent fuel pond for shipment off-site or use elsewhere, measure should be in place to ensure that no items containing nuclear material are included in the shipment. Again, such activities should be conducted by at least two people.

\section{Detection, Investigation and Resolution of Irregularities}

(NSS-25G 4.161-4.168) The research reactor should have a written plan outlining the approach to be taken if an irregularity is detected, including an accounting and control irregularity such as an item in the wrong location, an item missing at the time of physical taking, a broken tamper-indicating-device, etc. the plan should describe steps to be taken as part of the investigation and should require that the research reactor be cordoned off and that no nuclear material movements should occur until the problem is resolved.

\section{IN SUMMARY}

A facility NMAC system can be useful in protecting nuclear material from misuse by a facility insider. Enhancements to existing NMAC systems can be made at little additional cost to the facility, and these enhancements can be useful for nuclear security. A module has been prepared that will add NMAC to International Physical Protection Assessment Service (IPPAS) missions conducted by the IAEA Department of Nuclear Security. (As of October 2015 this module is in the draft stage.) Assessment of NMAC systems at the State and facility levels is available to determine whether they are sufficient to respond to nuclear security needs. This service is available upon request through IPPAS. Its purpose is to assist in strengthening the effectiveness of the NMAC system as part of the State's broader nuclear security regime and is available for research reactors as well as other facilities. 